\title{
Microbiological profile in community acquired pneumonia in children
}

\author{
Chaudhary G.S. ${ }^{1}$, Kumar $\mathrm{S}^{2}$, Kankane $\mathrm{A}^{3}$, Gupta $\mathrm{S}^{4}$ \\ ${ }^{1}$ Dr. Ghan Shyam Chaudhary, Assistant Professor, ${ }^{2}$ Dr. Sushil Kumar, JR III, ${ }^{3}$ Dr. Aradhana Kankane, Lecturer, \\ ${ }^{4}$ Dr. Sapna Gupta, Lecturer, all authors are affiliated with Department of Pediatrics, MLB Medical College Jhansi, Uttar \\ Pradesh, India.
}

Correspondence Author: Dr. Sushil Kumar, vill- Turkahiya, P.O.- Garaura Bazar, Distt- Maharajganj, PIN- 273305, Uttar Pradesh, India. Email: drgschaudhary@rediffmail.com

\begin{abstract}
Introduction: Community acquired pneumonia (CAP) refers to an infection of the lung by a variety of micro-organisms acquired outside the hospital setting. Methods and Material: It was prospective study conducted at department of Pediatrics of a tertiary care hospital of North India for a period of 12 months on children with community acquired pneumonia admitted in ward and emergency. Total 50 cases were enrolled in the study as recent WHO guidelines of community acquired pneumonia.Samples oforopharyngeal swab and blood for culture and sensitivity were collected with standard precautions from every child and sent for bacteriological lab within 30 minute of collection. Results: Out of 50 cases $36(72 \%)$ were diagnosed as pneumonia and $14(28 \%)$ were as severe pneumonia. On blood culture only $7(14 \%)$ had positive growth and on oropharyngeal swab culture $9(18 \%)$ had growth. Staphylococcus aureus and Streptococcus pneumonia were predominant organism on blood culture and oropharyngeal swab culture respectively. Conclusion: The overall rate of identification of bacterial etiology of CAP was low. Streptococcus pneumonae and Staphylococcus aureus predominate in oropharyngeal swab culture and blood culture respectively.
\end{abstract}

Key words: CAP, Blood culture, Oropharyngeal swab culture

\section{Introduction}

Community acquired pneumonia (CAP) is one of the most common infectious disease addressed by clinicians with annual incidence of 34 to 40 cases per 1000 in Europe and North America in children younger than 5 years of age $[1,2]$. Pneumonia are the number one cause of under-5 child mortality, responsible for nearly 400000 deaths in India annually [3]. The bacteriological profile of community acquired pneumonia is different in different countries and changing with time within the same country. Recent systematic reviews of childhood pneumonia etiology suggest that in developing countries, a few bacteria (S. pneumoniae and $\mathrm{H}$. influenzae) and viruses (respiratory syncytial virus, influenza virus) are associated with majority of childhood CAP[4].

Now a day, there is increase in resistance pattern of drugs due to overuse and inappropriate use of drugs by inexperienced fellow. Accurate, reliable and rapid determination of etiology in childhood CAP is important because it would influence individual

Manuscript received: 30 $^{\text {th }}$ April 2018

Reviewed: $8^{\text {th }}$ May 2018

Author Corrected: 14 $4^{\text {th }}$ May 2018

Accepted for Publication: $17^{\text {th }}$ May 2018 treatment decisions, antibiotic policy in the community, and also rational immunization policy at a national level. There is paucity of information regarding infectious etiology of CAP from Jhansi district (U.P., North India). The present work is aimed at identifying the common etiological agents and sensitivity pattern of bacteria of CAP in admitted cases in our institution.

\section{Methods}

Studysetting-This study was hospital based prospective study and was conducted in the department of Pediatrics at Maharani Laxmi Bai Medical College, Jhansi, after approval from ethical committee.

Study design- The study design was prospective and observational.

Study period- This study was conducted from October 2016 to October 2017.

Sample size- The sample size of study was 50 .

Inclusion criteria- Children aged 2 month to 12 years who presented with history of fever, cough and difficult 


\section{Editorial}

breathing fulfilling WHO case definition of CAP were enrolled. According to WHO [5] pneumonia and severe pneumonia are defined as follows-

Pneumonia: Patient present with cough, cold, fever, rapid breathing and chest indrawing, and tachypnoea is defined as respiratory rate $>60 /$ minute for infant $<2$ months, $>50 /$ minute for infants 2-12 months, $>40$ /minute for children $>12-60$ months, $>30 /$ minute for children $>60-144$ months [6].

Severe pneumonia: Patient present with sign and symptoms of pneumonia and associated with danger signs, like inability to drink, persistent vomiting, convulsion, lethargic or unconsciousness, stridor in calm child with severe malnutrition.
Exclusion criteria- Children with duration of illness $>7$ days, those who had received antibiotics for $>24$ hours at presentation or those with previous hospitalization for $>48$ hours in last 2 weeks, children with wheeze who had received a single dose of bronchodilator (salbutamol @ $0.15 \mathrm{mg} / \mathrm{kg}$ by nebulization) and symptom disappeared were excluded.

Sampling Method- Detailed history taken and examination done, sample for oropharyngeal swab and blood for culture and sensitivity were collected with standard precautions from every child and sent for bacteriological lab within 30 minute of collection.

Statistical Analysis- The data was collected and compiled systematically in tabular form and then analysed statistically.

\section{Results}

50 patients were enrolled in our study who fulfilled inclusion criteria. Majority of the patients i.e. 36 (72\%) were diagnosed as pneumonia and 14 (28\%) were as severe pneumonia. Out of 50 cases, $38(76 \%)$ belonged to age group of $2-$ 12 months followed by $5(10 \%)$ of age group 13-24 months. Among 50 cases $30(60 \%)$ were male, while 20 (40\%) were female, and M:F ratio was 1.5:1. Community acquired pneumonia was commonly found in lower socioeconomic status i.e. $28(56 \%)$ followed by lower middle class [11 (22\%)], suggesting higher frequency of community acquired pneumonia among lower socioeconomic class. It was observed that majority of community acquired pneumonia cases 29 $(58 \%)$ were having no infiltrates on chest $x$ ray. In present study, it was observed that on blood culture, growth was seen in only $7(14 \%)$ patients and majority of patients $43(86 \%)$ were growth negative. On comparison between pneumonia and severe pneumonia with results of blood culture we found that, organisms growth in blood culture was seen in 2 (5.5\%) patients with pneumonia and $5(35.7 \%)$ with severe pneumonia. On applying chi square test we found significant result $(\mathrm{P}$ value $=0.021130)$ which show growth on blood culture depend on severity of illness. Staphylococcus aureus growth was seen on blood culture in $4(8 \%)$ cases whereas $2 \%$ cases were positive each for Streptococcus pneumoniae, Pseudomonas, Hemophilus influenzae.On oropharyngeal swab culture 9 (18\%) patients had growth, in which 3(33.3\%) were with pneumonia and $6(66.7 \%)$ were with severe pneumonia. On statistical study we found $\mathrm{p}$ value $=0.01455$ which was significant. Out of 9 positive cases, Streptococcus pneumoniae was predominant $(5,10 \%)$ isolates followed by Staphylococcus aureus (2, 4\%), E.coli (1, 2\%) and klebsiella (1,2\%).

Table-1: Result of blood culture.

\begin{tabular}{|c|c|c|c|c|}
\hline Blood C \& S & Pneumonia & Severe pneumonia & Total & $\%$ \\
\hline Growth positive & 2 & 5 & 7 & $14 \%$ \\
\hline Growth negative & 34 & 9 & 43 & $86 \%$ \\
\hline Total & 36 & 14 & 50 & - \\
\hline
\end{tabular}

Table-2: Result of oropharyngeal swab culture.

\begin{tabular}{|c|c|c|c|c|}
\hline Oropharyngeal swab culture & Pneumonia & Severe Pneumonia & Total & $\%$ \\
\hline Growth Positive & 3 & 6 & 9 & $18 \%$ \\
\hline Growth negative & 33 & 8 & 41 & $82 \%$ \\
\hline Total & 36 & 14 & 50 & - \\
\hline
\end{tabular}


Editorial

Table- 3: Bacterial culture in clinical specimen.

\begin{tabular}{|c|c|c|}
\hline Organisms & Blood culture $\{\mathbf{n}=\mathbf{5 0}\}$ & Oropharyngeal swab culture $\{\mathbf{n}=\mathbf{5 0}\}$ \\
\hline Staphylococcus aureus & $4(8 \%)$ & $2(4 \%)$ \\
\hline Streptococcus pneumonia & $1(2 \%)$ & $5(10 \%)$ \\
\hline E.coli & - & $1(2 \%)$ \\
\hline Klebsiellaspp & - & $1(2 \%)$ \\
\hline Pseudomonas aeruginosa & $1(2 \%)$ & - \\
\hline Hemophilusinfluenzae & $1(2 \%)$ & - \\
\hline
\end{tabular}

\section{Discussion}

There has been evolution of antimicrobial resistant bacterial species due to factors like widespread and sometimes inappropriate use of antimicrobial agents and the increase in regional and international travel with which antimicrobial resistant bacteria cross geographical barriers. As there was limited data available on antibiotic resistance and sensitivity pattern, this study was undertaken.

The purpose of this study was to identify the health associated risks being faced in the present condition of hospitals, create a baseline antibiotic resistance data which can further form a base for formulating an effective infection control policy.

In our study, 50 patients who came with fever, cough and cold, rapid breathing, and refusal to feed were included after excluding the exclusion criteria. In present study, 36(72\%) subjects were diagnosed as pneumonia and 14 (28\%) diagnosed as severe pneumonia. Similar results were found in other studies done by different author $[6,7,8,9]$.

It was observed that majority of patients i.e. 76\% were belonged to age group 2-12 months followed by 13-24 months (10\%). In a study done in 2009 [7] majority of patients $65.8 \%$ belonged to age group 2-11 months followed by $34.2 \%$ belonged to 12-59 agegroup. Similar results were found byother researcher $[6,8,9]$.

This may be due to the immunological profile of these children, as the children grow they develop immunity against common organisms causing respiratory illness.

Male were affected more commonly than female (60\% Vs 40\%) with ratio 1.5:1 in our study. Joseph L. Mathew et al [8] also reported that CAP were relatively more common in male $(70.2 \% \mathrm{Vs} 29.8 \%)$ as also observed by others [6,9].

Anusmita Das et al and Yudhavir S. et al made similar observation. Present study were hospital based where male patients were more than female which might be due to gender biased health seeking behaviour of community.

Majority of subjects i.e. 28 (56\%) belonged to lower class, which is again similar to others study [11,14,15]. This may be due to unavailability of food, poor purchasing power; inappropriate distribution and inadequate utilization make the child vulnerable to malnutrition in deprived community.

The comparison of blood culture and oropharyngeal swab culture of various studies are given in table no. 4

Out of 50 patients $40(80 \%)$ were recovered and discharged successfully and $4(8 \%)$ were expired, remaining $6(12 \%)$ patients in our study either absconded or left against medical advice.

Out of 4 mortality 3 were from severe pneumonia group which can be concluded that mortality is more common in severe pneumonia age group.

Our finding is similar to the study conducted by Anusmita das et al (2016) who also reported similar mortality rate (i.e. $8.8 \%)[9]$. 
Editorial

Table-4: Comparison of organisms isolated in various study and their sensitivity pattern.

\begin{tabular}{|c|c|c|c|}
\hline $\begin{array}{l}\text { Sr. } \\
\text { No. }\end{array}$ & Author & Sample/Test & Result \\
\hline 1 & $\begin{array}{l}\text { Saha et al 1993-97 } \\
\text { [11] }\end{array}$ & $\begin{array}{l}\text { Blood culture, } \\
\text { CSF, Ear swab, } \\
\text { Pus }\end{array}$ & $\begin{array}{l}362 \text { Strep. pneumoniae strain were isolated } \\
64.1 \% \text { resistance cases with cotrimoxazole }\end{array}$ \\
\hline 2 & $\begin{array}{l}\text { The SENTRY } \\
\text { antimicrobial } \\
\text { surveillance study } \\
\text { (2000)[12] }\end{array}$ & Blood culture & $\begin{array}{l}\text { Organism recovered were Staph. aureus }(28 \%) \\
\text { Pseudomonas aeruginosa }(10 \%) \\
\text { Strep. pneumoniae }(9.1 \%) \text { Klebsiella }(7.5 \%) \\
\text { H. influenzae }(7.3 \%)\end{array}$ \\
\hline 3 & $\begin{array}{l}\text { V. L. Nag et al } 2001 \\
{[13]}\end{array}$ & Blood culture & $\begin{array}{c}\text { A total } 90 \text { strain of } \mathrm{H} \text {. influenzae were isolated } \\
\text { Frequency resistance with cotrimoxazole } 33.3 \% \text {, ampicillin } \\
21.1 \% \text {, cephalexin } 7.8 \% \text {, chloramphenicol } 2.5 \% \text {, } \\
\text { erythromycin \& tetracycline } 5 \% \text { each }\end{array}$ \\
\hline 4 & $\begin{array}{c}\text { Neuman MI et al } \\
2007-11[1\end{array}$ & Blood culture & $\begin{array}{l}\text { Strep. pneumoniae accounted for } 78 \% \text { of all detected } \\
\text { pathogen } \\
82 \% \text { susceptible for penicillin }\end{array}$ \\
\hline 5 & $\begin{array}{l}\text { Joseph et al 2011- } \\
\qquad 13[8]\end{array}$ & $\begin{array}{l}\text { Blood culture, } \\
\text { PCR, BAL }\end{array}$ & $\begin{array}{c}\text { NPA \& blood culture Yielded bacteria in only } 322(13.7 \%) \\
\text { and } 49(2.1 \%) \text { children respectively in NPA, Strep. } \\
\text { pneumoniae predominated, followed by H. influenzae } \\
(9.6 \%) \text { and Staph. aureus }(6.8 \%) \text {. In blood S. aureus }(30.6) \\
\text { dominated followed by S. pneumoniae }(20.4 \%) \text { and } \\
\text { Klebsiella, pneumoniae }(12.2 \%) \text { M. pneumoniae and C. } \\
\text { pneumoniae serology were positive in } 4.3 \% \text { and } 1.1 \% \\
\text { respectively }\end{array}$ \\
\hline 6 & $\begin{array}{l}\text { Anusmita das et al } \\
\text { 2013-14 [9] }\end{array}$ & Blood culture & $\begin{array}{c}\text { Blood culture was positive in } 3 \% \text { cases while } \\
\text { oropharyngeal positive in } 16.8 \% \\
\text { S. pneumoniae was major isolate }\end{array}$ \\
\hline 7 & $\begin{array}{l}\text { Yudhavir et al } \\
\text { (2016)[6] }\end{array}$ & Blood culture & $\begin{array}{l}\text { On blood culture S. aureus (10\%) predominated followed } \\
\text { by S. pneumoniae }(3.1 \%) \\
\text { On NPA Strep. pneumoniae was predominated } 18.5 \%\end{array}$ \\
\hline 8 & $\begin{array}{l}\text { Our study (2016- } \\
\text { 20017) }\end{array}$ & $\begin{array}{l}\text { Blood culture, } \\
\text { oropharyngeal } \\
\quad \text { culture }\end{array}$ & $\begin{array}{l}\text { On blood culture, staph. aureus was the most common } \\
\text { organism isolated and on oropharyngeal culture, strep. } \\
\text { pneumoniae was most common bacteria. }\end{array}$ \\
\hline
\end{tabular}

\section{Conclusion}

Thus following conclusions were made from our studyCAP is associated with lower socioeconomic status, emphasizing the role of overcrowding, under nutrition, literacy in causing pneumonia. Also malnutrition is the commonest finding associated with pneumonia. This sensitivity and resistance pattern can be used to formulate the antibiotic policy in children with community acquired pneumonia. Vaccination coverage needs to be improved especially against Streptococcus pneumoniae and other agents like Hemophilus influenzae so as to reduce the burden of morbidity and mortality in children with pneumonia. Blood culture and throat swab cultures were negative in many cases and clinical diagnosis and treat is still very useful in our locality. The community should be aware of the signs \& symptoms of CAP and its danger signs so that delay in treatment can be avoided.
What this study add to existing Knowledge: Blood culture and throat swab culture can help in diagnosis and management of resistant cases, but most ofresults comes negative so clinical diagnosis and treatment is still useful in community acquired pneumonia.

Contribution by Authors: Author 1 worked as guide, author 2 as PG student and authors 3 and 4 as co guides. All authors worked as Substantial contributions to the conception/ design of the work, the acquisition, analysis, interpretation of data for the work, drafting the work, revising it critically for important intellectual content, final approval of the version to be published, agreement to be accountable for all aspects of the work in ensuring that questions related to the accuracy or integrity of any part of the work are appropriately investigated and resolved. 


\section{Editorial}

Funding: Nil, Conflict of interest: None initiated, Perission from IRB: Yes

\section{References}

1. McIntosh K. Community-acquired pneumonia in children. N Engl J Med. 2002 Feb 7;346(6):429-37.

2. Rudan I, Tomaskovic L, Boschi-Pinto C, Campbell H; WHO Child Health Epidemiology Reference Group. Global estimate of the incidence of clinical pneumonia among children under five years of age. Bull World Health Organ.2004Dec;82(12):895-903.Epub 2005Jan 5

3. pneumonia among children under five years of age. Bull World Health Organ 2004; 82: 895-903.

4. DublishS.,Singh V. Pneumonia. In: Piyush G., PSN M, SiddhartR, Rakesh L. PG Text book of pediatrics. $1^{\text {st }}$ ed. New Delhi:Jaypee Brothers;2015. vol2. p 1720-28.

5. Gilani Z, Kwong YD, Levine OS, Deloria-Knoll M, Scott JA, O'Brien KL, Feikin DR. A literature review and survey of childhoodpneumoniaetiologystudies: 2000-2010. Clin Infect Dis. 2012 Apr;54 Suppl2:S1028. doi: 10.1093/cid/cir1053.

6. WHO. (2014) Revised WHO classification and treatment of childhood pneumonia at health facilities. Evidence Summaries, WHO 2014. Available at: http:// apps. who.int/iris/ bitstream/ 10665/ 137319/1/ 9789241507813 _eng.pdf (accessed 23 december 2017).

7. Shekhawat YS, Sharma P, Singh A, Payal V et al. Bacteriological and clinical profile of community acquired pneumonia in hospitalised children with associated co-morbidity in tertiary care centre of Western Rajasthan, India. Int J Contemppediatr. 2016 ;3 (4):1380-1384. Ijcp 20163682. doi: http//dx.doi.org/ 10. $18203 / 2349-3291$

8. Agweyu A, Kibore M, Digolo L. Prevalence and correlates of treatment failure among Kenyan children hospitalized with severe community- acquired pneumonia: a prospective study of the clinical effectiveness of WHO pneumonia case management guidelines.2014; 19 (11): 1310-1320. doi:10. 1111/ tmi. 12368.
9. Mathew J L, Singhi S, Ray P et al. Etiology of community acquired pneumonia among children in India: prospective, cohort study. PGIMER Chandigarh, India. J Glob Health. 2015;5(2):050418. Doi: 10.7189.

10. Das A, Patgiri SJ, Saikia L, Dowerah P, Nath R et al. Bacterial pathogens associated with communityacquired pneumonia in children aged below five years. Indian pediatrics, vol 53; 2016: 225-227.

11. N euman MI, Hall M, Lipsett SC, Hersh AL, Williams DJ, Gerber JS, Brogan TV, Blaschke AJ, Grijalva CG, Parikh K, Ambroggio L, Shah SS; Pediatric Research in Inpatient Settings Network. Utilityof Blood Culture Among Children Hospitalized with Community-Acquired Pneumonia. Pediatrics. 2017 Sep; 140 (3). pii: e20171013. doi: 10.1542/peds.20171013. Epub 2017 Aug 23.

12. Saha SK, Rikitomi N, Ruhulamin $M$ et al Antimicrobial Resistance and Serotype Distribution of Streptococcus pneumonia Strains Causing Childhood Infections in Bangladesh, 1993 to 1997.J Clin Microbiol. 1999 Mar; 37(3): 798-800.

13. Hoban DJ, Biedenbach DJ, Mutnick AH, Jones RN. Pathogen of occurrence and susceptibility patterns associated with pneumonia in hospitalizedpatients in North America: results of the SENTRY Antimicrobial Surveillance Study (2000). Diagn MicrobiolInfect Dis. 2003 Apr; 45(4):279-85.

14. Nag VL, Ayyagari A, Vnkatesh V, Ghar M, Yadav $\mathrm{V}$, Prasad KN et al. Drug resistant Haemophilus influenza from respiratory tract infection in a tertiary care hospital in North India. Indian J chest dis allied sci 2001; 43:13-17.

15. Kilabuko JH, Nakai S. Effects of cooking fuels on acute respiratory infections in children in Tanzania. Int J Environ Res Public Health. 2007 Dec;4(4):283-8.

16. Savitha MR, Nandeeshwara SB, Pradeep Kumar MJ, ul-Haque F, Raju CK. Modifiablerisk factors for acutelowerrespiratory tract infections. Indian J Pediatr. 2007 May;74(5):477-82.

\section{How to cite this article?}

Chaudhary G.S, Kumar S, Kankane A, Gupta S. Microbiological profile in community acquired pneumonia in children. Int J Pediatr Res. 2018;5(5):263-267.doi:10.17511/ijpr.2018.i05.04. 